\title{
POTENSI VEGETASI HUTAN KOTA DALAM REDUKSI EMISI KARBONDIOKSIDA (CO2) DI KOTA JAMBI
}

\section{Potential of Urban Forest Vegetation to Reduce Carbon Dioxide (CO2) Emission in Jambi City}

\author{
WATHRI FITRADA 1 , RIZKI ANDRE HANDIKA 2 , ZULI RODHIYAH ${ }^{3}$ \\ 'Environmental Engineering Dept., High School of Padang Industrial Technology \\ 2,3Environmental Engineering Dept., Faculty of Engineering, Jambi University \\ Email: rizki_ah@unja.ac.id
}

\begin{abstract}
Urban Forest is one of the Public Green Open Space which is controlling atmosfer, water, and soil pollution. Carbon dioxide $\left(\mathrm{CO}_{2}\right)$ is one of the emission substances of greenhouse gas sources. Increased concentration of $\mathrm{CO}_{2}$, which comes from burning fuel oil and gas, can cause various diseases, such as upper respiratory tract infections, heart disease, cancer and etc. Therefore, it is necessary to reduce $\mathrm{CO}_{2}$ emissions, which one of them is through the utilization of Public Green Open Space, especially urban forest. Jambi City as the most populous area in Jambi Province has high $\mathrm{CO}_{2}$ emission potential. The purpose of this research is to predict the potential of tree vegetation in urban forest in Jambi City in reducing $\mathrm{CO}_{2}$ gas. The research was conducted in 3 locations: Bagan Pete Urban Forest, Muhammad Sabki Urban Forest, and Pine Forest Kenali. The vegetation analysis was performed using the Quadrant Method, where the $10 \times 10$ m observation plot was determined randomly. Vegetation analysis at each location was conducted to obtain basal area, which then determined the potential of $\mathrm{CO}_{2}$ emission reduction. The basal area of the trees vegetation at each location was $72,72 \mathrm{~m}^{2} / \mathrm{Ha}, 25,45$ $\mathrm{m}^{2} / \mathrm{Ha}$ and $5,12 \mathrm{~m}^{2} / \mathrm{Ha}$. Reduction of $\mathrm{CO}_{2}$ of tree vegetation in urban forest in each location in sequence was $41386 \mathrm{Ton} / \mathrm{Ha} / Y$ ear, $14482.93 \mathrm{Ton} / \mathrm{Ha} / Y$ ear, 2916.94 Tons/Ha/Year. Bagan Pete Urban Forest has the highest reduction potential. Based on this research, total carbon dioxide emission reduction potential through urban forest in Jambi City was 58785,87 $\mathrm{Ton} / \mathrm{Ha} / \mathrm{Year}$.
\end{abstract}

Keywords: Reduction $\mathrm{CO}_{2}$; tree vegetation; basal sand; Jambi City

\begin{abstract}
Abstrak Hutan kota adalah salah satu ruang terbuka hijau masyarakat yang mengontrol pencemaran atmosfer, air dan tanah Karbon dioksida $\left(\mathrm{CO}_{2}\right)$ merupakan suatu substansi yang paling utama dari gas-gas rumah kaca dimana peningkatannya dapat terjadi dikarenakan penggunaan bahan bakar dan gas yang dapat menyebabkan berbagai penyakit seperti infeksi-infeksi saluran pernapasan bagian atas, sakit di bagian hati, kanker dan lain sebagainya. Oleh karena itu, merupakan hal yang penting untuk mengurangi emisi-emisi $\mathrm{CO}_{2}$ yang salah satunya dapat dilakukan melalui pemanfaatan ruang terbuka hijau publik, khususnya adalah hutan kota. Kota Jambi sebagai sebuah kota besar di Indonesia tentunya memiliki potensi emisi $\mathrm{CO}_{2}$ yang juga besar. Tujuan dari riset ini adalah untuk memprediksi potensi dari vegetasi pohon di hutan kota yang dimiliki oleh Kota Jambi dalam mengurangi emisi gas $\mathrm{CO}_{2}$. Riset ini dilakukan di tiga lokasi: hutan kota Bagan Pete, hutan kota Muhammad Sabki, dan hutan pinus Kenali. Analisis vegetasi dilakukan dengan metode kuadran dimana plot observasi pada $10 \times 10 \mathrm{~m}$ dilakukan untuk mendapatkan area basal secara acak. Pada setiap lokasi kemudian dideterminasi potensi pengurangan emisi $\mathrm{CO}_{2}$ masing-masing. Area basal dari vegetasi pohon-pohon di tiap lokasi didapatkan seluas 72,72 $\mathrm{m}^{2} / \mathrm{Ha}$ untuk hutan kota bagan Pete, 25,45 $\mathrm{m}^{2} / \mathrm{Ha}$ pada hutan kota Muhammad Sabki, dan $5,12 \mathrm{~m}^{2} / \mathrm{Ha}$ untuk hutan pinus Kenali. Sedangkan pengurangan $\mathrm{CO}_{2}$ dari vegetasi pohon di hutan kota pada tiap lokasi secara berurutan adalah 41.386 Ton/Ha/Tahun, 14.482,93 Ton/Ha/Tahun, 2.916,94 Tons/Ha/Tahun. Berdasarkan penelitian ini, hutan kota Bagan Pete memiliki potensi tertinggi dari ketiga hutan kota yang dimiliki oleh kota Jambi, dan total pengurangan emisi karbon dioksida di kota Jambi dari keberadaan hutan-hutan kota yang ada adalah sebesar 58.785,87 Ton/Ha/Tahun.

Kata Kunci: Pengurangan $\mathrm{CO}_{2}$; vegetasi kayu; tanah basal; kota Jambi
\end{abstract}




\section{PENDAHULUAN}

Indonesia merupakan salah satu negara dengan wilayah perkotaan yang terus mengalami peningkatan jumlah penduduk. peningkatan jumlah penduduk dalam periode 2005-2025 diproyeksikan akan mencapai $67,5 \%$. Kota Jambi dengan penduduk sejumlah 585.487 jiwa dikategorikan sebagai kota besar, dimana dengan luas wilayah $205,38 \mathrm{~km}^{2}$ memiliki kepadatan penduduk mencapai 2851 orang $/ \mathrm{km}^{2}$ (BPS Provinsi Jambi, 2017). Pertambahan jumlah penduduk dapat menyebabkan terjadinya peningkatan emisi, khususnya gas rumah kaca (GRK).

Ruang Terbuka Hijau (RTH) merupakan bagian dari ruang-ruang terbuka (open spaces) suatu wilayah perkotaan yang diisi oleh tumbuhan, tanaman, dan vegetasi (endemik, introduksi) guna mendukung manfaat langsung dan/atau tidak langsung yang dihasilkan oleh RTH dalam kota tersebut yaitu keamanan, kenyamanan, dan kesejahteraan serta keindahan wilayah perkotaan. RTH dapat dihubungkan peran dan potensinya dalam mereduksi gas karbon dioksida $\left(\mathrm{CO}_{2}\right)$ sebagai kontributor utama dari GRK yang menjadi penyebab terjadinya pemanasan global (Effendy, 2007; Pratiwi \& Hermana, 2013; Rawung, 2015). Reduksi $\mathrm{CO}_{2}$ terjadi dengan adanya daya serap tumbuhan, khususnya pohon, terhadap senyawa tersebut.

Hutan Kota merupakan bagian dari kawasan RTH Kawasan Perkotaan dengan fungsi salah satunya sebagai pengendali pencemaran dan kerusakan tanah, air, dan udara (Permendagri 1, 2007). Pemerintah Kota Jambi menetapkan melalui rencana tata ruang untuk melakukan pengembangan dan pengelolaan RTH Hutan Kota dengan luasan 524 Ha (Perda Jambi No. 9, 2013). Hutan Kota di Kota Jambi berada pada 2 pengelola yang berbeda, yaitu Dinas Lingkungan Hidup (DLH) Kota Jambi (Hutan Kota Muhammad Sabki dan Hutan Kota Bagan Pete) dan Dinas Kehutanan Provinsi Jambi (Taman Hutan Kenali). Total luasan Hutan Kota tersebut yaitu 68,7 Ha.

(Karakteristik Hutan Kota yang beragam menyebabkan adanya perbedaan potensi reduksi karbon, yaitu Taman Kota Monumen Nasional (19,8 ton per Ha), Hutan Pantai di Kepulauan Seribu (426,97 Ha) (Hikmatyar, Ishak, Pamungkas, Soffie, \& Rijaludin, 2015; Samsoedin \& Wibowo, 2012). Karena hal tersebut diperlukan perhitungan potensi reduksi karbon Hutan Kota di Kota Jambi, yaitu Hutan
Kota Muhammad Sabki, Hutan Kota Bagan Pete, dan Taman Hutan Kenali. Potensi tersebut dapat dijadikan dasar pengembangan dan pengelolaan RTH, khususnya Hutan Kota, di Kota Jambi.

\section{METODOLOGI}

Penelitian ini berlokasi di 3 Hutan Kota, yaitu Hutan Kota Muhammad Sabki, Hutan Kota Bagan Pete, dan Taman Hutan Kenali. Penelitian ini terdiri dari studi literatur, analisis vegetasi dan analisis daya serap $\mathrm{CO}_{2}$.

Studi literatur menjadi dasar pengembangan analisis vegetasi dan analisis daya serap yang akan digunakan pada penelitian ini. Data-data yang dikumpulkan terkait luasan total, luasan tutupan vegetasi, keanekaragaman jenis tumbuhan pada setiap kawasan Hutan Kota. Data tersebut didapatkan melalui DLH Kota Jambi dan Dinas Kehutanan Provinsi Jambi.

Analisis vegetasi menggunakan Metode Kuadran, dimana dikhususkan untuk pengambilan contoh vegetasi tumbuhan dengan fase pohon yang menjadi objek kajian. Metode ini menggunakan titik pengukuran dengan garis absis dan ordinat khayalan, sehingga pada setiap titik pengukuran terdapat empat kuadran. Pada setiap kuadran dipilih 2 pohon dengan jarak terdekat dari titik pengukuran dan ukur jaraknya dengan titik pengukuran, tinggi pohon, dan diameter batang. Jarak antar titik pengukuran adalah 20 meter.

Analisis daya serap $\mathrm{CO}_{2}$ dilakukan dengan melakukan pendekatan, yaitu menghitung rataan luas basal area per $\mathrm{Ha}$ individu pohon pada setiap Hutan Kota, kemudian dikalikan dengan kemampuan daya serap berdasarkan tipe tutupan vegetasi. Perhitungan tersebut akan menggunakan persamaan (1).

Daya Serap Terhadap $\mathrm{CO}_{2}=$ Daya Serap $\mathrm{CO}_{2} \times$ Luas Basal Area

\section{HASIL DAN PEMBAHASAN Kondisi Eksisting Hutan Kota}

Hutan kota merupakan salah satu komponen penting dalam upaya menangani dampak pencemaran udara oleh $\mathrm{CO}_{2}$. Oleh karena itu dirasa perlu untuk mengetahui potensi hutan kota terutama jenis vegetasi pohon dalam mereduksi $\mathrm{CO}_{2}$. Hasil pengamatan yang dilakukan pada ketiga lokasi analisis vegetasi menunjukkan tiga hutan kota tersebut memiliki karakteristik vegetasi yang berbeda. 
Taman Hutan Kenali memiliki luasan 10,25 Ha (Tabel 1) dengan struktur vegetasi yang relatif seragam. Beberapa jenis pohon yang dapat di temui di Taman Hutan kenali yaitu, Pinus (Pinus merkusi), Meranti (Shorea sp.), Mahoni (Swietenia mahagoni), Gaharu (Aquilaria sp.), Damar (Agathis sp.), Jati (Tectona grandis), dan Bulian (Euxideroxylon zwageri).

Hutan Kota Muhammad Sabki (Gambar 1) memiliki luasan sebesar $11 \mathrm{Ha}$ dengan vegetasi pohon yang lebih beragam dibandingkan dengan Taman Hutan Kenali. Beberapa jenis pohon yang dapat ditemukan di Hutan Kota Muhammad Sabki adalah Gaharu (Aquilaria sp.), Kayu manis (Cinnamomum sp.), Kayu putih (Melaleuca sp.), Bulian (Euxideroxylon zwageri), Cendana (Santalum sp.), Mahoni (Swietenia sp.), Sungkai (Peronema sp.), Jati (Tectona grandis), Rambutan (Nephelium lappaceum), Durian (Durio zibenthinus), Manggis (Garcinia mangostana) dan lain sebagainya.

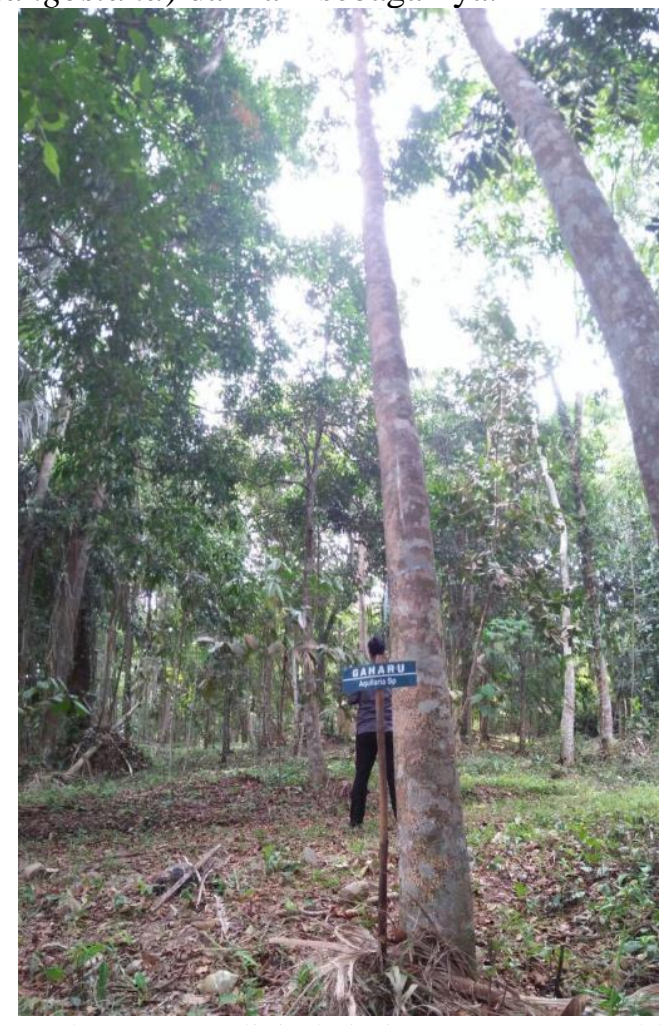

Gambar 1. Kondisi eksisting Hutan M. Sabki

Taman Hutan Kenali (Gambar 2) dikelola di bawah Dinas Kehutanan Provinsi Jambi, sedangkan Hutan Kota Muhammad Sabki dikelola di bawah Dinas Lingkungan Hidup Kota Jambi. Kedua Hutan kota tersebut diperuntukkan sebagai taman wisata, dimana struktur vegetasi tanaman dan jenis-jenis pohon yang berada pada dua hutan kota tersebut sudah di atur. Sedikitnya jumlah tegakan anakan maupun pancang mengindikasikan adanya upaya pengelolaan teratur berupa penyiangan terhadap vegetasi bawah hutan.

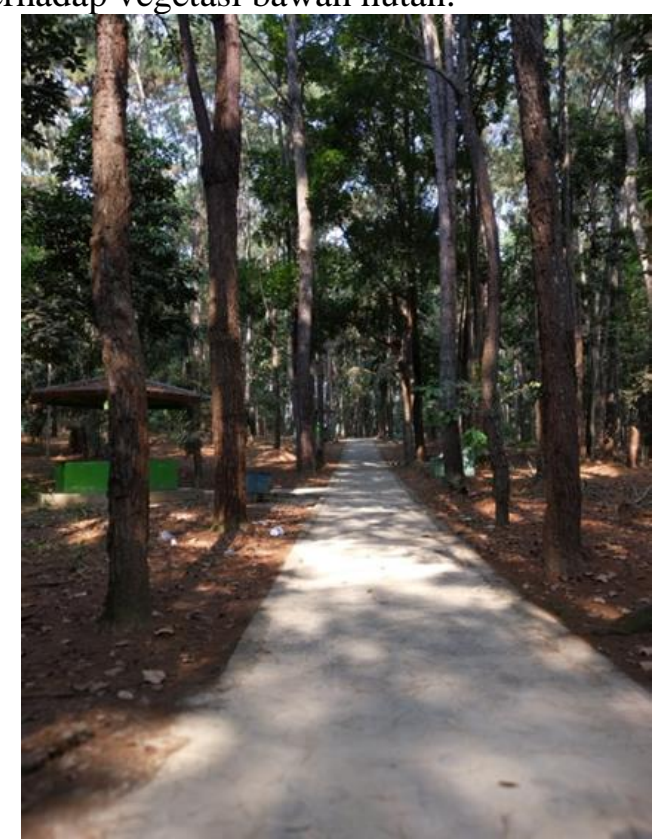

Gambar 2. Kondisi eksisting Taman Hutan Kenali

Hutan Kota Bagan Pete (Gambar 3) juga dikelola oleh Dinas Lingkungan Hidup Kota Jambi. Namun berbeda halnya dengan Hutan Kota M. Sabki, pada Hutan Kota Bagan Pete, struktur vegetasi masih tergolong rapat. Pada lokasi tersebut masih dapat dijumpai adanya pohon, anakan dan pancang serta semak perdu yang menutupi struktur vegetasi bawah hutan. Berdasarkan analisis vegetasi ditemukan beberapa jenis pohon, yaitu Macaranga sp., Litsea sp., Agathis sp., Peronema sp., Calophyllum sp., dan Hevea brasiliensis.

\section{Analisis Vegetasi}

Analisis vegetasi dilakukan dalam upaya untuk mengetahui struktur dan komposisi dalam suatu ekosistem hutan. Namun dalam hal ini, analisis dilakukan hanya pada beberapa aspek yang berhubungan dengan prediksi potensi hutan kota sebagai pereduksi $\mathrm{CO}_{2}$. Dari hasil pengamatan yang dilakukan didapatkan luas total basal area terkecil terdapat pada Taman Hutan Kenali sebesar $5,12 \mathrm{~m}^{2} / \mathrm{Ha}$ dan yang terluas yaitu Hutan Kota Bagan Pete sebesar $72,72 \mathrm{~m}^{2} / \mathrm{Ha}$ (Tabel 1). 
Tabel 1: Analisis Basal Area Pohon

\begin{tabular}{lcc}
\hline $\begin{array}{l}\text { Nama Hutan Kota }\left(\begin{array}{c}\text { Lua } \\
\text { RTH })\end{array}\right. \\
\text { s } \\
\left(\begin{array}{c}\text { Ha } \\
)^{*}\end{array}\right.\end{array}$ & $\begin{array}{c}\text { Total Basal } \\
\text { Area }\left(\mathrm{m}^{2} / \mathrm{Ha}\right)\end{array}$ \\
\hline $\begin{array}{l}\text { Hutan Kota } \\
\text { Muhammad Sabki }\end{array}$ & 11 & \\
& & 25,45017 \\
\hline $\begin{array}{l}\text { Hutan Kota Bagan } \\
\text { Pete }\end{array}$ & 41, & 72,72722 \\
\hline $\begin{array}{l}\text { Taman Hutan } \\
\text { Kenali/Hutan Pinus }\end{array}$ & 10, & 5,12581 \\
\hline
\end{tabular}

*Sumber: Dinas Lingkungan Hidup Kota

Jambi, 2018

Total area basal ditentukan oleh beberapa faktor, yaitu umur, curah hujan, kesuburan tanah, rasio C:N tanah, ketinggian, suhu, dan biomassa. Data total basal area di Hutan Kota Muhammad Sabki berbeda dengan penelitian sebelumnya, yaitu $18,02 \mathrm{~m}^{2} / \mathrm{Ha}$ (Mahya Ihsan, Ummi Mardhiah Batubara, 2016). Perbedaan tersebut disebabkan perbedaan waktu pengambilan data atau umur dari individu pohon yang diukur. Total basal area hutan tropis borneo, selain berkorelasi positif dengan biomassa, dilaporkan memiliki korelasi dengan rata-rata curah hujan, kesuburan tanah, rasio C:N tanah, ketinggian, suhu (Slik et al., 2010).

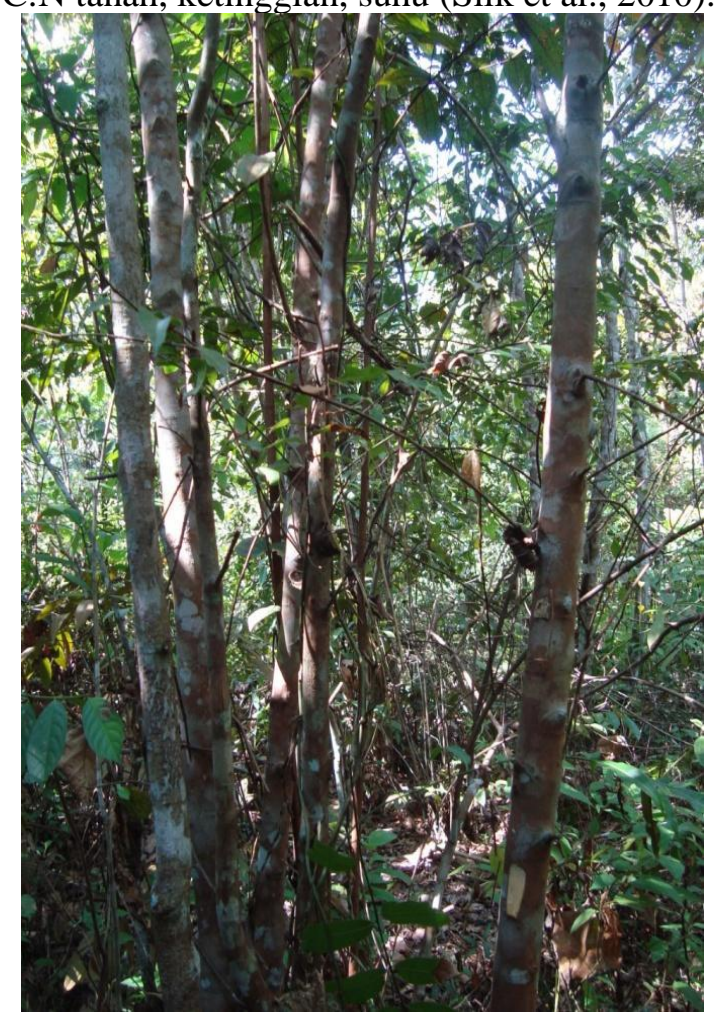

Gambar 3. Kondisi eksisting Hutan Kota Bagan Pete

Total area basal akan menunjukkan penguasaan individu pohon pada suatu komunitas vegetasi, yang akan berhubungan dengan biomassa. Biomassa dapat dihubungkan dengan kemampuan tumbuhan dalam menjerap $\mathrm{CO}_{2}$. Selain hal tersebut, Rawung (2015) melaporkan vegetasi pohon jati memiliki kemampuan menyerap $\mathrm{CO}_{2}$ lebih tinggi dibandingkan dengan bentuk vegetasi semak belukar dan sawah. Setiap jenis tumbuhan memiliki karakteristik yang berbeda, salah satu diantaranya jumlah daun. Kemampuan serapan karbondioksida tiap pohon juga dapat dipengaruhi oleh jumlah daun yang ada (Purwaningsih, 2007).

Hutan Kota Bagan Pete dengan memiliki total basal area terbesar (Gambar 4) mengindikasikan umur dari vegetasi tertua. Kedua hutan kota dengan total basal area lebih rendah memiliki karakteristik yang sama yaitu vegetasi hutan sekunder dengan adanya upaya penanaman dan penyiangan terhadap vegetasi herba. Penyiangan tersebut menjadikan laju peningkatan luas basal area menjadi lebih rendah.

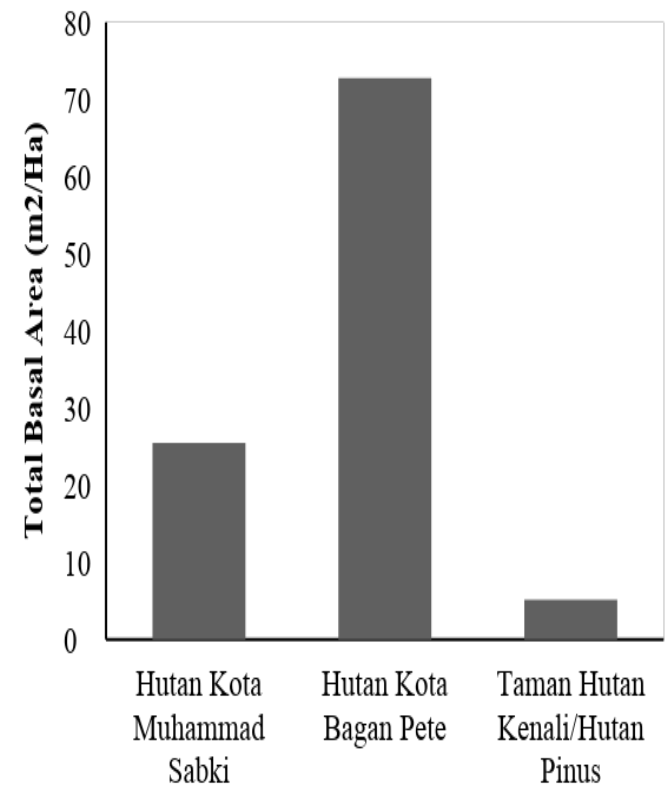

Gambar 4. Total Basal Area

Analisis Daya Serap Hutan Kota Eksisting

Pada penelitian ini diasumsikan bahwa vegetasi pohon memiliki kemampuan yang lebih dalam menyerap karbondioksida dibandingkan dengan pancang, anakan dan semak/perdu. Hal ini diperkuat dengan hasil penelitian yang menyatakan bahwa rasio antara luas basal area 
dan jumlah karbon tergantung pada ukuran dari suatu pohon (Torres A.B., 2013). Sehingga, pohon dengan diameter yang besar akan berkontribusi pada luas basal area dan jumlah karbon yang dapat diserap tanaman tersebut.

Hasil terendah pada perhitungan daya serap $\mathrm{CO}_{2}$ yang diperoleh pada penelitian ini terdapat pada Taman Hutan Kenali yaitu sebesar 2916,94 Ton/Ha/Tahun, sedangkan nilai daya serap $\mathrm{CO}_{2}$ tertinggi terdapat pada vegetasi pohon pada Hutan Kota Bagan Pete 41386 Ton/Ha/Tahun (Gambar 5). Hal tersebut dapat terjadi karena rapatnya jarak satu tanaman dengan tanaman lainnya. Peningkatan jarak tanam antar pohon dapat meningkatkan potensi reduksi $\mathrm{CO}_{2}$ (Al-Hakim, 2014). Faktorfaktor yang dapat mempengaruhi potensi reduksi zat pencemar adalah umur tanaman, jenis tanaman, kerimbunan, ketinggian tanaman, jumlah emisi karbon, suhu, kecepatan angin, kepadatan, dan ketinggian bangunan (Kaule, 2000).

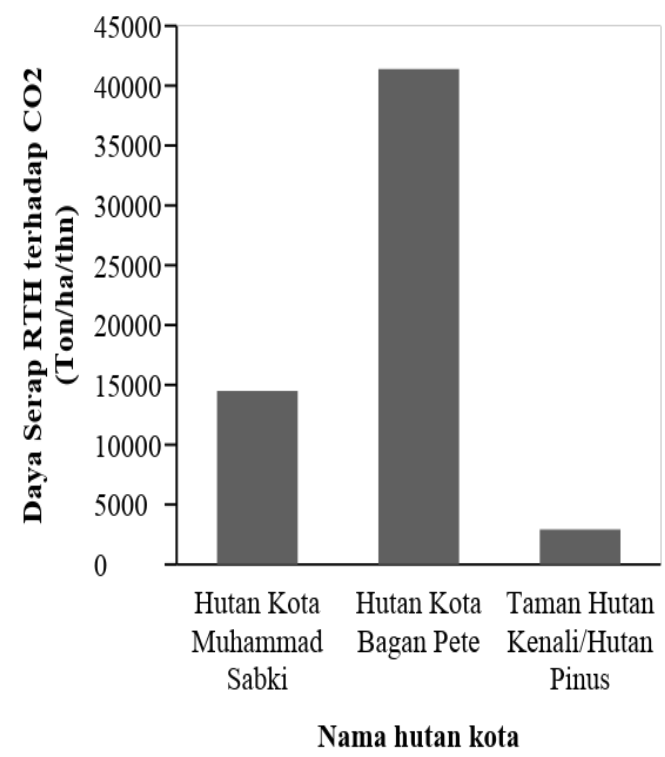

Gambar 5. Daya serap RTH terhadap gas karbondioksida $\left(\mathrm{CO}_{2}\right)$

Dari pengamatan di lokasi penelitian hasil tersebut sangat memungkinkan terjadi. Vegetasi pohon yang berada di Taman Hutan Kenali lebih jarang, jika dibandingkan dengan vegetasi pohon yang ada di Hutan Bagan Pete. Hutan Kota dengan vegetasi pohon yang jarang, menyerap $\mathrm{CO}_{2}$ lebih rendah, dibandingkan dengan hutan kota dengan vegetasi yang rapat (Dahlan, 2007). Dilihat dari tren yang dihasilkan pada gambar 1 dan 2, maka akan terlihat adanya hubungan antara luas basal area dengan daya serap RTH terhadap $\mathrm{CO}_{2}$.

\section{KESIMPULAN}

Hutan Kota yang berada di Kota Jambi memiliki potensi reduksi karbondioksida yang berbeda. Hutan Kota Bagan Pete memiliki potensi reduksi tertinggi diikuti oleh Hutan Kota Muhammad Sabki dan Taman Hutan Kenali. Usia dan peruntukan kawasan menjadi hal utama menyebabkan tingginya potensi Hutan Kota Bagan Pete. Pengelolaan yang baik diperlukan untuk menjaga keberadaan vegetasi, khususnya pohon.

\section{UCAPAN TERIMAKASIH}

TERIMA KASIH KEPADA LEMBAGA PENELITAN DAN PENGABDIAN MASYARAKAT UNIVERSITAS JAMBI YANG TELAH MENDANAI PENELITIAN INI, SEHINGGA PENELITIAN YANG BERJUDUL "POTENSI VEGETASI HUTAN KOTA DALAM REDUKSI EMISI KARBONDIOKSIDA $\left(\mathrm{CO}_{2}\right)$ DI KOTA JAMBI" DAPAT TERLAKSANA.

\section{DAFTAR PUSTAKA}

Al-Hakim, A. H. (2014). Evaluasi Efektivitas tanaman dalam mereduksi Polusi Berdasarkan Karakter Fisik Pohon Pada Jalur Hijau Jalan Pajajaran Bogor. Institut Pertanian Bogor.

BPS Provinsi Jambi. (2017). Provinsi Jambi Dalam Angka 2017. Jambi: BPS Provinsi Jambi.

Dahlan, E. N. (2007). Analisis Kebutuhan Luasan Hutan Kota Sebagai Sink Gas Co 2 Antropogenik Dari Bahan Bakar Minyak Dan Gas. Sekolah Pascasarjana Institut Pertanian Bogor.

Effendy, S. (2007). Keterkaitan Ruang Terbuka Hijau dengan Urban Heat Island Wilayah JABOTABEK. Sekolah Pascasarjana, Institut Pertanian Bogor.

Hikmatyar, M. F., Ishak, T. M., Pamungkas, A. P., Soffie, S., \& Rijaludin, A. (2015). Estimasi karbon tersimpan pada tegakan pohon di hutan pantai pulau kotok besar, bagian barat, kepulauan seribu. AlKauniyah Jurnal Biologi, 8(1), 40-45. Retrieved from http://103.229.202.68/dspace/handle/123 $456789 / 31029$

Kaule, G. (2000). Ecologically Orientated Planning. Frankfurt: Peter Lang.

Mahya Ihsan, Ummi Mardhiah Batubara, I. O. S. (2016). Biomassa Diatas Permukaan Tanah Pada Pohon Dan Sapling Di Ruang Terbuka Hijau Muhammad Sabki Propinsi Jambi. SEMIRATA 2015, 4(1). 
Retrieved from http://jurnal.untan.ac.id/index.php/semira ta2015/article/view/13756/12332

Perda Jambi No. 9. Rencana Tata Ruang Wilayah Kota Jambi Tahun 2013-2033 (2013). Indonesia.

Permendagri 1. Permendagri No 12007 tentang Penataan Ruang Terbuka Hijau Kawasan Perkotaan (2007). Indonesia.

Pratiwi, W. A. K., \& Hermana, J. (2013). Analisis Pengurangan Emisi CO2 Melalui Ketersediaan Ruang Terbuka Hijau di Gedung Perkantoran Pemerintah Kota Surabaya. Teknik POMITS, 2(3), 214217.

Purwaningsih, S. (2007). Kemampuan Serap Karbondioksida pada tanaman hutan Kota di Kebun Raya Bogor. Institut Pertanian Bogor.

Rawung, F. (2015). Efektivitas Ruang Terbuka Hijau (RTH) dalam Mereduksi Emisi Gas Rumah Kaca (GRK) di Kawasan Perkotaan Boroko. Media Matrasain, 12(2), 17-32. Retrieved from http://ejournal.unsrat.ac.id/index.php/jm $\mathrm{m} /$ article/view/9204

Samsoedin, I., \& Wibowo, A. (2012). Analisis Potensi dan Kontribusi Pohon di Perkotaan dalam Menyerap Gas Rumah Kaca. Studi Kasus: Taman Kota Monumen Nasional, Jakarta. JURNAL Penelitian Sosial Dan Ekonomi Kehutanan, 9(1), 42-53. Retrieved from http://forda-

mof.org/files/Jurnal_Sosek_9-1-2012-

5.Ismayadi_n_Ari_Wibowo.pdf

Slik, J. W. F., Aiba, S. I., Brearley, F. Q., Cannon, C. H., Forshed, O., Kitayama, K., ... van Valkenburg, J. L. C. H. (2010). Environmental correlates of tree biomass, basal area, wood specific gravity and stem density gradients in Borneo's tropical forests. Global Ecology and Biogeography, 19(1), 50-60. https://doi.org/10.1111/j.14668238.2009.00489.x

Torres A.B., \& L. J. C. (2013). Using basal area to estimate aboveground carbon stocks in forests: La Primavera Biosphere's Reserve, Mexico. Forestry: An International Journal of Forest Research, 86(2), 267-281. Retrieved from https://academic.oup.com/forestry/article/ $86 / 2 / 267 / 548410$ 